\title{
Virtual Medical Education During COVID-19 Pandemic in Iran: A Qualitative Study of Perspectives on Challenges and Strategies
}

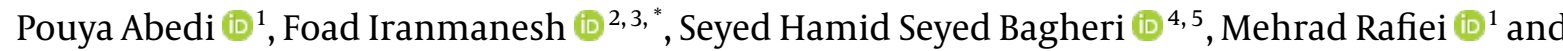 \\ Hojat Afshari (iD ${ }^{1}$ \\ ${ }^{1}$ Student Research Committee, Rafsanjan University of Medical Sciences, Rafsanjan, Iran \\ ${ }^{2}$ Department of Endodontics, Dental School, Rafsanjan University of Medical Sciences, Rafsanjan, Iran \\ ${ }^{3}$ Education Development Center, Rafsanjan University of Medical Sciences, Rafsanjan, Iran \\ ${ }^{4}$ Non-Communicable Diseases Research Center, Rafsanjan University of Medical Sciences, Rafsanjan, Iran \\ ${ }_{5}^{5}$ Department of Pediatric Nursing, Nursing and Midwifery School, Rafsanjan University of Medical Sciences, Rafsanjan, Iran \\ "Corresponding author: Department of Endodontics, Dental School, Rafsanjan University of Medical Sciences, Rafsanjan, Iran. Email: foad.iranmanesh@gmail.com
}

Received 2021 November 16; Accepted 2022 January 26.

\begin{abstract}
Background: The COVID-19 pandemic led to virtual education for students, causing many problems in many countries, including Iran.

Objectives: This study explains the challenges of virtual medical education and strategies to promote it from the perspective of students, faculty members, and educational staff of Rafsanjan University of Medical Sciences to meet the needs and expectations of learners and educators.

Methods: This qualitative study was conducted using a conventional content analysis approach in 2021. The sample size criterion was to achieve data saturation, based on which 14 faculty members, students, and educational staff were selected by purposive sampling and interviewed using a semi-structured interview guide. The accuracy of the data was ensured through participants' views, peer review, and an external observer. MAXQDA version 10 was used to facilitate the analysis process.

Results: Based on the analysis, 4 main categories for virtual education challenges, including managerial factors, problems related to the nature of virtual education, infrastructural factors, and individual factors, were extracted. Further, 4 main categories, including improving management, improving education, providing infrastructure, and informing and empowering educators, students, and educational staff, were extracted to promote virtual education during the COVID-19 pandemic at Rafsanjan University of Medical Sciences.

Conclusions: The challenges to which virtual education is faced and unique strategies to promote it during the COVID-19 pandemic were discussed. Understanding these challenges helps to their elimination and provides practical solutions for them. These challenges and solutions can lead to effective virtual education and thus increase the quality of learning.
\end{abstract}

Keywords: COVID-19, Virtual Medical Education, Challenges, Strategies, Qualitative Research

\section{Background}

The sudden outbreak of COVID-19 in early 2020 posed many challenges to the world's healthcare systems and also affected medical education (1). With the onset of the COVID-19 epidemic, all countries, including Iran, emphasized the observance of social distancing, which led to virtual education and online classes for students, with great effort and many problems (2-4). Issues such as launching elearning courses, establishing a virtual university, and creating electronic content have changed the teaching and learning process and created a new educational pattern (5).

The virtual education systems play a significant role in this era. These systems help the educator to plan, carry out, manage, and follow the teaching process (6). In fact, elearning platforms have become very popular in the teaching process, especially in medical education, as they create a global space that is easily accessible through laptops, smartphones, tablets, etc., and because in some cases, its content can be used at any time (7). Learning management system (LMS) is one of the approaches in virtual education, which organizes and manages e-learning activities such as enrollment, testing, holding courses, creating curricula, conversations, etc. (8).

In the field of medical sciences in Iran, teaching was first presented irregularly through social networks; how-

Copyright (c) 2022, Journal of Medical Education. This is an open-access article distributed under the terms of the Creative Commons Attribution-NonCommercial 4.0 International License (http://creativecommons.org/licenses/by-nc/4.0/) which permits copy and redistribute the material just in noncommercial usages, provided the original work is properly cited. 
ever, over time, medical universities were required to use the NAVID system (ie, an academic learning management system) as a centralized educational system. Students and faculty members benefited from the capabilities of this system; thus, virtual education, with all its shortcomings, overcame conventional face-to-face education (2). However, the continuous separation of e-learning from the real environment undoubtedly brought about limitations such as lack of interaction in this type of space $(9,10)$. On the other hand, virtual education will not be suitable for all types of education (11). Some studies have shown that despite the benefits of virtual education in the development of the educational system, the implementation of this project in universities has always been followed by obstacles and problems. For example, the lack of skilled staff and the shortage of financial and physical resources to equip universities with computer systems and facilities are the main problems in the development of such universities $(12,13)$.

Since students are one of the most important beneficiaries of virtual education and are also in a close and tangible relationship with it, they can express its problems in terms of content, structure, and quality of education (14). Moreover, the opinions of students, faculty members, and educational staff in reviewing these pieces of training will be useful for educational planners and policymakers and will improve the quality of virtual education.

\section{Objectives}

Given the importance of examining these opinions and considering the lack of qualitative studies on the problems of virtual medical education (which provides a broader and more objective view of the subject under study) and the fact that the facilities and experiences of different universities in virtual education are different from each other (which creates different challenges), this study aimed to explore the challenges of virtual medical education and the views of students, faculty members, and educational staff of Rafsanjan University of Medical Sciences to meet the needs and expectations of learners and educators.

\section{Methods}

This qualitative study was conducted using a conventional content analysis approach at Rafsanjan University of Medical Sciences in 2021. The sample size criterion in this study was similar to qualitative studies (ie, achievement of data saturation where no new data were obtained) (15). Accordingly, 5 faculty members, 6 students, and 3 educational staff were selected by purposive sampling based on maximum diversity in the field of study and demographic characteristics. The participants were aware of and experienced virtual education and were approved by the Education Development Center (EDC) in terms of activity.

The interviews were conducted face to face in accordance with COVID-19 protocols. Data were collected by semi-structured and open-ended interviews, and the participants' responses guided the interview process. Each interview was started with 3 main questions: (i) What are the challenges (main problems) related to the virtual education system during the COVID-19 pandemic based on your experience? (ii) What aspects (strengths) of this educational system are you pleased with? (iii) According to your experience, what are the most important factors for improving and increasing the quality of virtual education? The interviews were continued with probing questions. Interviews were conducted at each participant's workplace and were recorded for subsequent analysis.

Data analysis was performed by conventional content analysis based on the method proposed by Graneheim and Lundman (16). Therefore, each interview was transcribed and converted into a Microsoft Word file and read line-byline to identify meaning units. The analysis process was performed by summarizing the meaning units and converting them into codes, subcategories, and categories under valid rules $(16,17)$.

\subsection{Accuracy and Robustness of the Findings}

Using integration in the selection of participants, the review of the manuscripts by participants, and peer review by the research colleagues, efforts were made to increase the acceptability of data and reinforce reliability by complete and continuous recording of the researcher's activities on data collection and analysis.

The credibility of data was determined by confirming a summary of students' statements in each interview, asking probing questions during the interviews to ensure the correct interpretation of participants' statements, and reviewing the manuscripts by the research team (P. A., M. R., and H. A.). Codes and categories were extracted by 2 authors to establish dependability. Continuous and comparative analysis of data and a continuous review of the research analysis process were performed to increase the confirmability. Transferability was achieved by sharing the results with 2 external faculty members, who confirmed the findings, in a situation similar to that of the participants. To facilitate the analysis process in this research in the first and second stages, MAXQDA version 10 (VERBI $\mathrm{GmbH}$, Berlin, Germany) was used. 


\subsection{Ethical Considerations}

This study was confirmed by the Ethics Committee of Rafsanjan University of Medical Sciences (code: IR.RUMS.REC.1400.065). Further, the interviews were conducted after a brief explanation of the study to each participant. Moreover, the principles of confidentiality of information were observed, and informed consent was obtained to conduct and record the interview.

\section{Results}

The participants included 6 females and 8 males, with an age range of 23 - 45 years. In this study, based on qualitative content analysis, 4 main categories for virtual education challenges and 4 main categories for promoting virtual education strategies at Rafsanjan University of Medical Sciences were extracted during the COVID-19 pandemic. A total of 605 primary raw codes were extracted from the participants' interviews regarding these categories without considering the overlap (Tables 1 and 2).

\subsection{Challenges of Virtual Education}

\subsubsection{Managerial Factors}

Managerial factors are management problems related to how virtual education is organized and implemented at the university level. The subcategories in this area included "lack of rules and regulations," "executive problems," and "lack of supervision over educators' performance."

In the subcategory of lack of rules and regulations, issues such as the lack of a specific program to present courses and the lack of a specific teaching protocol were raised. In the subcategory of executive problems, issues such as the difficult implementation of the protocol were raised. Regarding the lack of supervision, one of the faculty members stated, "What are the rules and regulations and standards to evaluate whether the educators follow the instructions? Do they follow the rules and regulations or not? The university education system has to do this" (P2).

\subsubsection{Problems of the Nature of Virtual Education}

Some problems were related to the teaching and learning methods and the nature of distance learning. This category included the subcategories of "problems before teaching," "problems during teaching," and "problems after teaching."

In the subcategory of problems before teaching, issues such as incorrect educational design and content problems were raised. In the subcategory of problems during teaching, issues such as problems of educator-student interaction, lack of trust in cyberspace, and the timeconsuming nature of virtual education were raised. Regarding the educators' interaction problems, one of the faculty members stated,

"If the educator in the classroom feels that the student is not learning well, he or she can either lower the level of teaching to be desirable for the student or repeat it, but in virtual education, the educator cannot get the necessary feedback from the students" (P8).

In the category of problems after teaching, issues such as the stressful nature of the virtual testing for the student, question design problems for educators, test design problems, unfair test results, and students' cheating were raised. In the case of the latter, one of the students reported, "On the one hand, there is cheating, from cheating with a friend to looking at a pamphlet .... This itself lowers the quality of the evaluation" (P6).

\subsection{Infrastructural Factors}

This category included the subcategories of "software problems," "hardware problems," and "Internet problems." Software problems included the NAVID system, WhatsApp, and Adobe Connect software. Regarding the problems of the NAVID system, one of the faculty members stated,

"The NAVID system itself was disrupted several times, which was annoying. This system was not designed for such a situation at all and was a test version. Now, it has entered a basic operational work ... . For example, the tests, ... the usernames and passwords were not complete and had to be defined. The student never cared what his/her username and password were" (P7).

Hardware problems included issues such as university server problems and a lack of content production facilities for educators. In the Internet problems category, one of the faculty members stated, "There are some students who live in the countryside and do not have access to the Internet, facilities, and technology" (P8).

\subsection{Individual Factors}

There are problems in the field of virtual education directly related to individuals, which can be solved by the student or faculty member individually. The subcategories that fell into this category included "educatorrelated problems," "student-related problems," and "common educator-student problems."

The educator-related problems included the unavailability of educators, the irregularity of educators in teaching, and the inefficiency of educators. Regarding the irregularity of educators, one of the faculty members stated that: 
Abedi P et al.

Table 1. Categories and Subcategories of Virtual Education Challenges at Rafsanjan University of Medical Sciences During the COVID-19 Pandemic Along with Examples of Concepts Reported by Interviewees

\begin{tabular}{|c|c|c|}
\hline Category & Subcategory & Examples of Primary Codes \\
\hline Managerial factors & $\begin{array}{l}\text { Lack of rules and regulations; Executive problems; } \\
\text { Lack of supervision over the educators' performance }\end{array}$ & $\begin{array}{l}\text { Lack of a specific protocol for virtual education (P9, } \\
\text { P10, and P12); Lack of evaluation and monitoring } \\
\text { system by the university (P2, P11, and P11); Difficult } \\
\text { implementation of the protocol (P13 and P14) }\end{array}$ \\
\hline $\begin{array}{l}\text { Problems related to the nature of virtual } \\
\text { education }\end{array}$ & $\begin{array}{l}\text { Problems before teaching; Problems during } \\
\text { teaching; Problems after teaching }\end{array}$ & $\begin{array}{l}\text { Problems of educator-student interaction (P8, P6, } \\
\text { and P2); Problems of students' cheating in virtual } \\
\text { exams (P11, P7, and P6); Inadequacy of virtual } \\
\text { education for practical lessons (P9, P7, and p6) }\end{array}$ \\
\hline Infrastructure factors & $\begin{array}{l}\text { Software problems; Hardware problems; Internet } \\
\text { problems }\end{array}$ & $\begin{array}{l}\text { Lack of content production facilities for educators } \\
\text { (P6, P3, and P7); Problems of the NAVID system (P4, } \\
\text { P6, and P7); Inadequate Internet bandwidth (P11, P5, } \\
\text { and P2) }\end{array}$ \\
\hline Individual factors & $\begin{array}{l}\text { Educator-related problems; Student-related } \\
\text { problems; Common student-educator problems }\end{array}$ & $\begin{array}{l}\text { Lack of students' use of the content and } \\
\text { participation in classes (P1, P10, and P13); Educators' } \\
\text { insufficient education (P4, P5, and P7); Lack of } \\
\text { experience on the part of educators, students, and } \\
\text { university staff in virtual education (P9, P7, and P2) }\end{array}$ \\
\hline
\end{tabular}

Table 2. Categories and Subcategories of Virtual Education Promotion Strategies at Rafsanjan University of Medical Sciences During the COVID-19 Pandemic Along with Examples of Concepts Mentioned by the Interviewees

\begin{tabular}{|c|c|c|}
\hline Category & Subcategory & Examples of Primary Codes \\
\hline Improving management & $\begin{array}{l}\text { Monitoring and evaluation; Executive solutions; } \\
\text { Establishing rules and regulations }\end{array}$ & $\begin{array}{l}\text { Monitoring the performance of educators (P13, P6, } \\
\text { and P1); Differentiating educators with strong and } \\
\text { weak performance (P1, P7, and P9); Implementing the } \\
\text { mentoring plan (P2 and P7) }\end{array}$ \\
\hline Promoting education & $\begin{array}{l}\text { Correct educational design; Promoting educational } \\
\text { content; Promoting tests }\end{array}$ & $\begin{array}{l}\text { Holding question and answer sessions (P2, P5, and } \\
\text { P12); Dividing students' assessment into several } \\
\text { parts (P2, P3, and P14); Considering an editor to } \\
\text { produce content for educators (P6 and P11) }\end{array}$ \\
\hline Providing infrastructure & $\begin{array}{l}\text { Providing the Internet; Providing facilities and } \\
\text { equipment }\end{array}$ & $\begin{array}{l}\text { Creating an electronic test hall (P3, P7, and P11); } \\
\text { Creating a content production center for educators } \\
\text { (P6, P8, and P11); Providing free Internet traffic (P1, P2, } \\
\text { and P12) }\end{array}$ \\
\hline $\begin{array}{l}\text { Informing and empowering educators, } \\
\text { students, and education staff }\end{array}$ & $\begin{array}{l}\text { Changing the attitude of students and educators; } \\
\text { Promoting knowledge; Promoting skills }\end{array}$ & $\begin{array}{l}\text { Holding training workshops for educators, students, } \\
\text { and educational staff (P3, P4, P5, and P6); Repeating } \\
\text { training and holding retraining courses for } \\
\text { educators (P4, P9, and P13); Promoting virtual } \\
\text { education culture (P7, P8, and P13) }\end{array}$ \\
\hline
\end{tabular}

"They had misinterpretations of the virtual space. They assumed that they could teach at any time if they wanted, but it is not so. The educator thought that because it was virtual, then he/she could run his/her class at any time of the semester" (P7).

The student-related problems included the adverse effects of virtual education on students' learning, students' non-use of content and participation in educational processes, and the problems of new students. Regarding the students' non-use of content and participation in educational processes, one of the faculty members stated that:

"Many students do not do the tasks in virtual education and take them from their friends. Many students do not get involved in class discussions, which may be due to various reasons such as their endangered position in the classroom or being ridiculed by their friends, and stu- dents' participation in conversations and class discussions is very low" (P10).

Common problems for educators and students included lack of experience and misconceptions about virtual education. Lack of experience itself was divided into 2 parts, including insufficient knowledge and insufficient skill.

\subsection{Strategies to Promote Virtual Education}

\subsubsection{Improving Management}

The educational management of the university can make policies and ratify and implement laws, which can indicate a roadmap for all members of the university and solve many problems. Its subcategories included "supervision and evaluation," "executive strategies," and "the formulation of laws and regulations." Regarding the supervi- 
sion and evaluation, one of the students reported that "The deputy and the person in charge of the supervisory department should see how their educator is producing and evaluating the content, in which case the content will have better quality" (P9).

\subsubsection{Promoting Education}

In this study, improving education means improving teaching and learning. Education can be promoted in many ways, from changing the attitudes of students and educators to providing the necessary infrastructure. The subcategories of this domain included "proper educational design," "promoting educational content," and "promoting tests." Improving the educational content included such things as the need to provide photos and videos in clinical courses, the need for explanations along with slides, and considering an editor for the educational content.

The test promotion subcategory included items such as "strategies to reduce cheating and multi-part evaluation." One of the students said, "for virtual education, their criteria should not be exams ... but you learn when you have to do a task. The best evaluation method is to evaluate it in detail, from the same tasks, for example" (P1).

\subsubsection{Providing Infrastructure}

Providing infrastructure is one of the basic principles to advance educational goals. If there is sufficient infrastructure, we can see the improvement of education. This category included the subcategories of "promoting the Internet" and "supplying facilities and equipment." As for the provision of facilities and equipment, one of the educational staff stated, "do you think that our faculty and university have the facilities for such a system? There should be an electronic test hall and 30 or 40 computers" (P3).

\subsubsection{Informing and Empowering Educators, Students, and Ed- ucational Staff}

Knowledge enhancement is one of the most fundamental events that can happen in virtual education. When something is done with sufficient knowledge and awareness, the vision of educators and students will be improved, and it will be easier to accept it. This category included the subcategories of "changing the attitudes of students and educators toward virtual education," "knowledge development," and "skill development." Regarding the changing the attitude of students and educators toward virtual education, one of the faculty members stated that

"The next challenge is to resist change, which applies to both educators and students; that is, if we want to make a change in education now, there will be resistance against it. Two years after this situation, educators still believe that virtual education has no advantage, so we have to make this change in both students and educators" (P8).

One of the issues raised in the field of knowledge promotion was holding training workshops that play a significant role in the educational status of educators and students directly and indirectly.

\section{Discussion}

The present qualitative study was conducted to explore the views of students, faculty members, and educational staff regarding the challenges and solutions of virtual education during the COVID-19 pandemic. The challenges mentioned in the interviews were divided into 4 categories, and the solutions were classified into 4 categories. The results of a qualitative study by Dennison et al showed that valuable information resources, motivation, accessibility and efficiency, and awareness-raising were among the opportunities for virtual education to support the changing of health behaviors (10).

According to the findings of the present study, the first challenging experience at Rafsanjan University of Medical Sciences was managerial challenges such as legislation and law enforcement in the university, which were also among the challenges raised in previous studies $(18,19)$. Although Rafsanjan University of Medical Sciences has implemented policies to increase the awareness and knowledge of the faculty members by running training programs on how to use the virtual education system (20), in some cases, this issue makes virtual education more difficult at university due to the novelty of the program and lack of effective support (21).

To ensure a flexible move from face-to-face learning to e-learning, educational policies need to be changed, such as support for top management, curricula, and instructors' adherence to university rules for using e-learning in the learning process (22). In the opinion of the participants in the present study, identifying educators with better performance in e-learning can be used as an incentive to use this system in the university, which will help improve the management. While the faculty members have to adjust the tests according to their online status, it is difficult to monitor how they give online tests and ensure that students do not cheat on online tests (23). In addition, it is not possible to run laboratory, practical, and performance tests online, and students who do not have access to the Internet show severe weakness in the test process, which will negatively affect their grade point average (GPA) (23).

Another study suggested that given the possibility of group counseling on responses (a type of cheating), a 
mechanism should be provided for virtual individual evaluation. One of the proposed methods was to hold open book exams (24). Educator-student interaction and participation in course topics are important elements of elearning. In addition, several studies have pointed out that learning is a very complex and social phenomenon that is enhanced by educator-learner interaction and feedback (25). In line with the present study, the interviewees in a similar study showed that they did not have enough time for interaction and participation. In some courses, especially clinical training courses, the focus is merely on effective e-learning, and assessment is not appropriate (24). In the present study, to strengthen this relationship, it was suggested to hold separate question and answer sessions, but the limited class time may restrict such a thing.

The third challenge was the infrastructural factors in the university, such as software and hardware problems and LMS (NAVID). In the COVID-19 pandemic, many universities lacked the infrastructure and immediate resources to facilitate online learning (24). A review by Sahu showed that many students in the COVID-19 pandemic did not have access to laptops and the Internet at home for elearning (23). Universities need to provide the necessary hardware, software, and Internet connection because universities must constantly update the necessary technological resources. Therefore, it seems that infrastructure problems and shortcomings have a negative effect on attitudes toward the use of e-learning. As shown in several studies, the quality of the system can directly and significantly affect the tendency to use e-learning. The low quality of some of the contents produced was also one of the challenges mentioned by other studies (22). The suggestion presented in the present study was to establish a content production center by the university. Challenges related to individual factors can be due to the lack of a culture of e-learning or a negative attitude toward it. Further, the lack of information about technology can reduce the motivation of students and educators.

In line with the results of this study, the findings of other studies in Iran showed that in addition to infrastructure issues, cultural issues were also barriers to the use of e-learning (26). Universities should focus on creating a culture of e-learning systems among students and faculty members through training courses on the benefits of e-learning systems and developing their information technology (IT) skills. This is because if learners have sufficient computer skills and a positive attitude toward interaction with the e-learning system, it will lead to success in accepting the e-learning system (22). Currently, one of the educational problems in the world is poor virtual education of practical skills and course credits, and no specific method for learning all skills has been introduced so far.
This learning situation will seriously question the learners' skills (23). Therefore, one of the challenges is to address the situation of skill training through virtual education. It should also be noted that e-learning approaches should be tailored to the local situations and needs (27).

\subsection{Conclusions}

The main challenges of virtual education at Rafsanjan University of Medical Sciences during the COVID-19 pandemic included managerial factors, problems of the nature of virtual education, infrastructural factors, and individual factors. The main strategies to promote virtual education also included improving management, promoting education, providing infrastructure, and informing and empowering the educators, students, and educational staff. Identifying these challenges and turning them into opportunities, and reviewing the proposed solutions can lead to effective teaching/learning and thus increase the quality of education. It is hoped that the findings of this study can pave the way for decision-makers to better manage virtual education.

\section{Acknowledgments}

The authors thank all the students, faculty members, and educational staff of Rafsanjan University of Medical Sciences who participated in the study.

\section{Footnotes}

Authors' Contribution: Study concept and design: F. I.; Collecting data: H. A., M. R., and P. A.; Analysis and interpretation of data: S. S., H. A., and P. A.; Drafting of the manuscript: P. A.; Critical revision of the manuscript for important intellectual content: F. I. and S. S.

Conflict of Interests: None to declare.

Ethical Approval: This study was confirmed by the Ethics Committee of Rafsanjan University of Medical Sciences (code: IR.RUMS.REC.1400.065).

Funding/Support: There were no sources of external financial support for this study. No honorarium, grant, or other forms of payment were given to anyone to produce the manuscript.

\section{References}

1. Mian A, Khan S. Medical education during pandemics: a UK perspective. BMC Med.2020;18(1):1-2. doi:10.1186/s12916-020-01577-y. [PubMed: 32268900]. [PubMed Central: PMC7141929].

2. Ghafourifard M. The promotion of virtual education in Iran: The potential which turned into reality by Coronavirus. Iran J Med Educ. 2020;20:33-4. 
3. Sajed AN, Amgain K. Corona Virus Disease (COVID-19) Outbreak and the Strategy for Prevention. Euro J Med Sci. 2020;2(1):1-4. doi: 10.46405/ejms.v2i1.38.

4. Centers for Disease Control and Prevention (U.S.). Implementation of mitigation strategies for communities with local COVID-19 transmission. CDC; 2020, [cited 3/21/2020].

5. Khan BH.The people-process-product Continuum in e-learning: the e-learning P3 model. Educ Technol. 2004;44(5):33-40.

6. Ülker D, Yllmaz Y. Learning Management Systems and Comparison of Open Source Learning Management Systems and Proprietary Learning Management Systems. J Syst Integr. 2016;7(8):18-24. doi: 10.20470/jsi.v7i2.255.

7. Lewis KO, Cidon MJ, Seto TL, Chen H, Mahan JD. Leveraging elearning in medical education. Curr Probl Pediatr Adolesc Health Care. 2014;44(6):150-63. doi: 10.1016/j.cppeds.2014.01.004. [PubMed: 24981664].

8. Haghshenas M. A model for utilizing social Softwares in learning management system of E-learning. Iran Distance Educ J. 2019;1(4):2538.

9. Islam N, Beer M, Slack F. Managing Online Presence in the E-Learning Environment: Technological Support for Academic Staff. J Educ Train Stud. 2015;3(3):91-100. doi: 10.11114/jets.v3i3.744.

10. Dennison L, Morrison L, Conway G, Yardley L. Opportunities and challenges for smartphone applications in supporting health behavior change: qualitative study. J Med Internet Res. 2013;15(4). e86. doi: 10.2196/jmir.2583. [PubMed: 23598614]. [PubMed Central: PMC3636318].

11. Talebian S, Mohammadi HM, Rezvanfar A. Information and Communication Technology (ICT) in Higher Education: Advantages, Disadvantages, Conveniences and Limitations of Applying E-learning to Agricultural Students in Iran. Procedia: Soc Behav Sci. 2014;152:300-5. doi:10.1016/j.sbspro.2014.09.199.

12. Schroeder A, Minocha S, Schneider C. The strengths, weaknesses, opportunities and threats of using social software in higher and further education teaching and learning. J Comput Assist Learn. 2010;26(3):159-74. doi: 10.1111/j.1365-2729.2010.00347.x.

13. Afzalkhani M, Ghods S. Evaluation of the Situation of Intelligent Secondary Schools Deployment in Semnan Province from the Viewpoint of Managers and Teachers. Int J Inf Commun Technol. 2003;2(1):23-39.

14. Henzi D, Davis E, Jasinevicius R, Hendricson W, Cintron L, Isaacs M. Appraisal of the dental school learning environment: the students' view. J Dent Educ. 2005;69(10):1137-47. [PubMed: 16204680].

15. Speziale HS, Streubert HJ, Carpenter DR. Qualitative research in nursing: Advancing the humanistic imperative. Lippincott Williams \& Wilkins; 2011.
16. Graneheim UH, Lundman B. Qualitative content analysis in nursing research: concepts, procedures and measures to achieve trustworthiness. Nurse Educ Today. 2004;24(2):105-12. doi: 10.1016/j.nedt.2003.10.001. [PubMed:14769454].

17. Hsieh HF, Shannon SE. Three approaches to qualitative content analysis. Qual Health Res. 2005;15(9):1277-88. doi:10.1177/1049732305276687. [PubMed: 16204405].

18. Gregory S. Teaching Higher Education Students with Diverse Learning Outcomes in the Virtual World of Second Life®. Transforming Virtual World Learning. Emerald Group Publishing; 2011. p. 327-56. doi: 10.1108/s2044-9968(2011)0000004017.

19. Shafiei Sarvestani M, Mohammadi M, Afshin J, Raeisy L. Students' experiences of e-learning challenges; a phenomenological study. J Virtual Learn Med Sci. 2019;10(3):1-10.

20. Iranmanesh F, Ostadebrahimi H, Mirzazadeh A, Azin M. Performance Report of Distance Learning at Rafsanjan University of Medical Sciences During the COVID-19 Pandemic. J Rafsanjan Univ Med Sci. 2020;19(4):423-8. doi: 10.29252/jrums.19.4.423.

21. Dedeilia A, Sotiropoulos MG, Hanrahan JG, Janga D, Dedeilias P, Sideris M. Medical and Surgical Education Challenges and Innovations in the COVID-19 Era: A Systematic Review. In Vivo. 2020;34(3 Suppl):160311. doi: 10.21873/invivo.11950. [PubMed: 32503818]. [PubMed Central: PMC8378024].

22. Almaiah MA, Al-Khasawneh A, Althunibat A. Exploring the critical challenges and factors influencing the E-learning system usage during COVID-19 pandemic. Educ Inf Technol (Dordr). 2020:1-20. doi: 10.1007/s10639-020-10219-y. [PubMed: 32837229]. [PubMed Central: PMC7243735].

23. Sahu P. Closure of Universities Due to Coronavirus Disease 2019 (COVID-19): Impact on Education and Mental Health of Students and Academic Staff. Cureus. 2020;12(4). doi: 10.7759/cureus.7541.

24. Hayat AA, Keshavarzi MH, Zare S, Bazrafcan L, Rezaee R, Faghihi SA, et al. Challenges and opportunities from the COVID-19 pandemic in medical education: a qualitative study. BMC Med Educ. 2021;21(1):247. doi: 10.1186/s12909-021-02682-z. [PubMed: 33926439]. [PubMed Central: PMC8082480].

25. Regmi K, Jones L. A systematic review of the factors - enablers and barriers - affecting e-learning in health sciences education. BMC Med Educ. 2020;20(1):1-18. doi: 10.1186/s12909-020-02007-6. [PubMed: 32228560]. [PubMed Central: PMC7106784].

26. Khadivar S, Rahmani Y. Virtual University obstacles and challenges in the electronic city. Bimonth Artif Intell Instrument. 2014;8(4):186-205.

27. Aung TN, Khaing SS. Challenges of Implementing e-Learning in Developing Countries: A Review. Genetic and Evolutionary Computing. Springer; 2015. p. 405-11. doi: 10.1007/978-3-319-23207-2_41. 